\title{
Uptake of catecholamines by human cardiac muscle in vitro ${ }^{1}$
}

\author{
M. C. PETCH AND W. G. NAYLER \\ From the National Heart Hospital and Cardiothoracic Institute, 2 Beaumont Street, London
}

SUMMARY Noradrenaline uptake was studied using heart muscle from 102 patients undergoing cardiac surgery. Slices of right atrium were incubated in Krebs-Henseleit solution containing $1.3 \times 10^{-7} \mathrm{M}$ ${ }^{3} \mathrm{H}$-noradrenaline. Uptake was lower in failing heart muscle and was inhibited not only by increasing the noradrenaline concentration in the incubating medium but also by adding the drugs desmethylimipramine, amitryptyline, and ouabain.

The adrenergic neurone possesses an efficient uptake mechanism whose properties are well known. Noradrenaline is the preferred substrate but the process exhibits stereochemical and structural specificity so that adrenaline and dopamine are also substrates whereas isoprenaline is not. Uptake is energy and temperature dependent; it obeys enzyme kinetics and is inhibited by a range of drugs including cocaine, the tricyclic antidepressants, and the cardiac glycosides (Iversen, 1967, 1973; von Euler, 1972). Neuronal uptake of adrenaline and noradrenaline removes these catecholamines from the extracellular space and thus terminates their effects.

This paper describes, for the first time, the neuronal uptake of catecholamines by human cardiac muscle. The experiments were performed in vitro.

\section{Patients and methods}

(1) PATIENTS

Samples of cardiac muscle were obtained from 102 patients (64 male and 38 female) undergoing open heart surgery at the National Heart Hospital or Harley Street Clinic. Their ages ranged from 7 to 70 years (mean $48 \cdot 4$ ). Only patients undergoing aortic or mitral valve surgery or coronary artery bypass operations were studied and they were divided into those with and those without cardiac

\footnotetext{
'Supported by grants from The British Heart Foundation and the Clinical Research Committee of the National Heart and Chest Hospitals.
}

Received for publication 28 March 1978 failure as diagnosed by the referring physician; the former had all been treated with digoxin and diuretics. Right atrial muscle was taken from the atrial appendage, and left ventricular muscle from the papillary muscle of patients undergoing mitral valve replacement.

\section{(2) CATECHOLAMINE UPTAKE EXPERIMENTS} The samples were collected in ice-cold KrebsHenseleit solution containing $2 \mathrm{~g}$ glucose, $20 \mathrm{mg}$ ascorbic acid, and $10 \mathrm{mg}$ ethylenediaminotetraacetic acid per litre; the calcium concentration was $1.275 \mathrm{M}$ (Iversen, 1963). The samples were cut into $0.5 \mathrm{~mm}$ slices using a tissue slicer and preincubated in the solution at $37^{\circ} \mathrm{C}$ for $15 \mathrm{~min}$. Both before collection and throughout the experiments the KrebsHenseleit solution was gassed with 5 per cent carbon dioxide and 95 per cent oxygen. Blanks were prepared by incubating the tissue at $0^{\circ} \mathrm{C}$. Estimations were made in triplicate. ${ }^{3} \mathrm{H}$-noradrenaline was added to give the desired final concentration in $5 \mathrm{ml}$ of solution; any drugs were added at the beginning of the preincubation time.

After incubation the slices were harvested by filtration, washed with a further $15 \mathrm{ml}$ of KrebsHenseleit solution, and weighed. The slices were dissolved in $1 \mathrm{ml}$ Soluene 350 (Packard Inst. Co.) at $50^{\circ} \mathrm{C}$ and their radioactivity counted in a Packard TRICARB liquid scintillation spectrometer using $10 \mathrm{ml}$ Dimilume (Packard Inst. Co.) as the scintillant.

The results were corrected for quenching using the automatic external standard and expressed as a concentration ratio by comparison of disintegrations per minute (d.p.m.) per mg tissue and d.p.m. per $\mu l$ medium. 
(3) DRUGS AND REAGENTS

DL-(7-3H) noradrenaline hydrochloride (specific activity $15 \mathrm{Ci} / \mathrm{mmol}$, DL-(7-3H)), isoprenaline (specific activity $10 \mathrm{Ci} / \mathrm{mmol}$ and $\mathrm{DL}-(7-3 \mathrm{H})$ ), adrenaline (specific activity $14.3 \mathrm{Ci} / \mathrm{mmol}$ ) were supplied by the Radiochemical Centre, Amersham, U.K. The following drugs were kindly donated by the pharmaceutical industry-desipramine $\mathrm{HCl}$ (Geigy), lignocaine $\mathrm{HCl}$ (Astra), amitriptyline $\mathrm{HCl}$ (Merck, Sharp and Dohme), dl propranolol HCl (Imperial Chemical Industries Ltd.); ouabain was supplied by British Drug Houses.

\section{(4) StATISTICS}

Results in the text are expressed as the mean \pm standard deviation. Their significance was determined using Student's $t$ test.

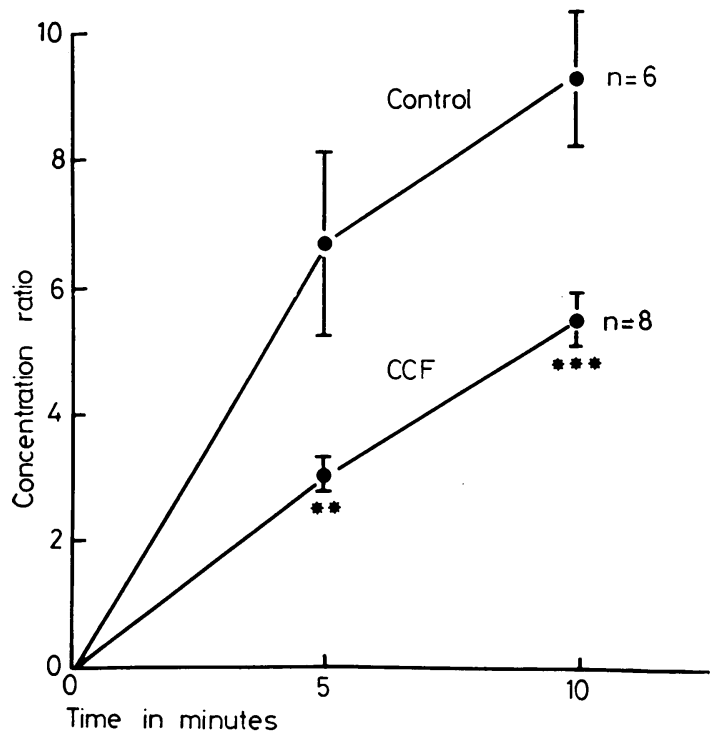

Fig. 1 Uptake of ${ }^{3} \mathrm{H}$-noradrenaline by human right atrial muscle from patients with and without congestive cardiac failure $(C C F)$. The results are expressed as the mean $\pm S E M$ of $n$ experiments. ${ }^{*} P<0.05,{ }^{* *} P<0.01$, $\star \star \star P<0.001$ in this and subsequent figures.

Table $1{ }^{3} \mathrm{H}$-noradrenaline uptake by human right atrium in vitro

\begin{tabular}{lll}
\hline Time $($ min $)$ & \multicolumn{2}{l}{ Concentration ratio mean $\pm S D$} \\
\cline { 2 - 3 } & $\begin{array}{l}\text { Aortic valve } \\
\text { replacement }\end{array}$ & $\begin{array}{l}\text { Mitral valve } \\
\text { replacement }\end{array}$ \\
\hline 5 & $2 \cdot 72 \pm 0.98$ & $3.07 \pm 1.24$ \\
10 & $4 \cdot 75 \pm 1.52$ & $5.56 \pm 1.87$ \\
20 & $9 \cdot 22 \pm 3.89$ & $9.07 \pm 3.66$ \\
40 & $14.60 \pm 3.20$ & $14.06 \pm 3.64$ \\
60 & $20.94 \pm 6.14$ & $20.42 \pm 6.15$ \\
& $\mathrm{n}=7$ & $\mathrm{n}=9$ \\
\hline
\end{tabular}

\section{Results}

After 10 minutes incubation in Krebs-Henseleit solution containing $1.3 \times 10^{-7} \mathrm{M}^{3} \mathrm{H}$-noradrenaline the concentration ratio for a 'control' group of 6 patients was $9 \cdot 28 \pm 2 \cdot 84$. These patients were undergoing coronary artery bypass operations, and had normal cardiac function at rest; none had ever received treatment with digoxin or diuretics. In 8 patients with cardiac failure undergoing aortic or mitral valve replacement the corresponding concentration ratio was $5.46 \pm 1.53$ (Fig. 1). When the experiments were repeated using ${ }^{3} \mathrm{H}$ sorbitol, no significant difference between the two groups was detected; the mean concentration ratio for the two groups combined was $0.36 \pm 0.01$ $(n=9)$. There was no difference between the samples from patients undergoing aortic, as compared with mitral valve replacement though the incubation time was extended to one hour (Table 1).

Slices of left ventricular muscle accumulated $1.3 \times 10^{-7} \mathrm{M}^{3} \mathrm{H}$-noradrenaline more slowly than right atrial muscle so that after one hour of incubation the concentration ratio was $8 \cdot 86 \pm 3 \cdot 12$. This was significantly lower than the concentration ratio obtained for right atrial samples taken from patients with cardiac failure, which was $20.65 \pm 6 \cdot 15$ (Fig. 2).

The effect of noradrenaline concentration on the initial uptake velocity was examined using right atrial samples from patients with cardiac failure and a 5-minute incubation time; the concentration ratio fell as the noradrenaline concentration in the incubating medium increased (Table 2). While it

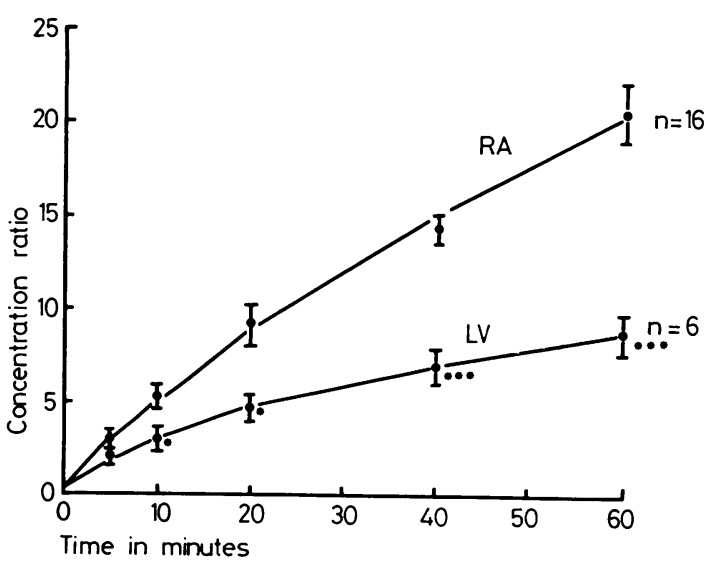

Fig. $2{ }^{3}$ H-noradrenaline uptake by human right atrial $(R A)$ and left ventricular (LV) muscle taken from patients with congestive cardiac failure. 
Table 2 Effect of increasing noradrenaline concentration on uptake

\begin{tabular}{lll}
\hline $\begin{array}{l}\text { Noradrenaline } \\
\text { concentration }(\mu M)\end{array}$ & Concentration ratio & $\begin{array}{l}\text { Uptake velocity } \\
n m / \text { min per } g\end{array}$ \\
\hline 0.13 & $4.12 \pm 0.56$ & 0.08 \\
0.30 & $3.14 \pm 0.63$ & 0.12 \\
0.90 & $2.53 \pm 0.59$ & 0.26 \\
3.00 & $1.95 \pm 0.34$ & 0.51 \\
9.00 & $1.63 \pm 0.34$ & 0.96 \\
15.00 & $1.58 \pm 0.40$ & 1.45 \\
& $\mathrm{n}=8$ & \\
\hline
\end{tabular}

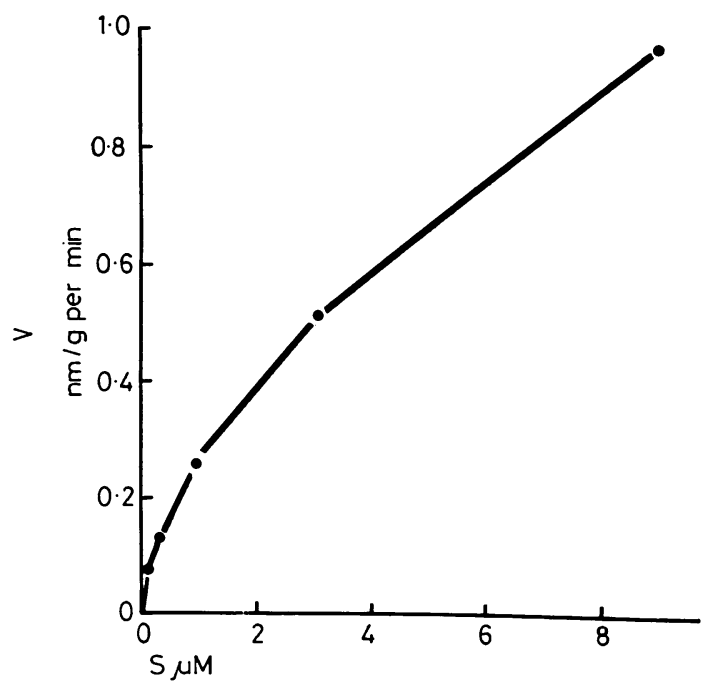

Fig. 3 Initial velocity of noradrenaline uptake $(V)$ plotted against substrate concentration $(S)$ for right atrial muscle slices taken from patients with congestive cardiac failure.

was possible to calculate the initial uptake velocity, the results obtained using ${ }^{3} \mathrm{H}$-noradrenaline concentrations over $3 \mu \mathrm{M}$ were less accurate as the concentration ratios approached the blank value (Fig. 3). Nevertheless, the uptake velocity did not increase linearly as the noradrenaline concentration was increased and a reciprocal plot of the 0.3 , 0.9 , and $3.0 \mu \mathrm{M}$ values approximates to a straight line; the Michaelis constant and maximum uptake velocity were $1.5 \mu \mathrm{M}$ and $0.7 \mathrm{nmol} / \mathrm{min}$ per $\mathrm{g}$, respectively (Fig. 4).

The uptake of $1.3 \times 10^{-7}{ }^{3} \mathrm{H}$-noradrenaline by slices of right atrial muscle was inhibited by the tricyclic antidepressants desipramine and amitriptyline (Table 3); lignocaine and propranolol were without effect. Ouabain inhibited noradrenaline uptake in a group of 4 patients undergoing coronary artery bypass surgery, none of whom had ever received treatment with digitalis glycosides (Table 4). The same effect could be detected in patients with cardiac failure but the inhibition was less pronounced.

Adrenaline was taken up by slices of right atrial muscle from patients with cardiac failure though the concentration ratios were lower than those for noradrenaline. After 10 minutes of incubation with $1.3 \times 10^{-7} \mathrm{M}$ adrenaline the ratio was $3.30 \pm$ $0.56(n=7)$; after 10 minutes of incubation in the presence of $10^{-6} \mathrm{M}$ desipramine the concentration ratio was $1 \cdot 58 \pm 0 \cdot 24.10^{-5} \mathrm{M}$ isoprenaline was not



Fig. 4 Lineweaver Burke plot of Fig. 3.

Table 3 Effect of drugs on noradrenaline uptake

\begin{tabular}{lll}
\hline & Concentration ratio & $P$ \\
\hline Control & $6.72 \pm 1.84$ & \\
Desmethylimipramine & $2 \cdot 18 \pm 0.46$ & $<0.001$ \\
Amitriptyline & $2.99 \pm 0.47$ & $<0.001$ \\
Lignocaine & $6.44 \pm 2.19$ & NS \\
Propranolol & $6.14 \pm 1.95$ & NS \\
& $n=8$ & \\
\hline
\end{tabular}

All drug concentrations $=10^{-6} \mathrm{M}$

Table 4 Effect of ouabain on noradrenaline uptake

\begin{tabular}{ll}
\hline & Concentration ratio \\
\hline Control & $8 \cdot 43 \pm 0.36$ \\
Ouabain $10^{-8} \mathrm{M}$ & $6 \cdot 28 \pm 0.60$ \\
Ouabain $10^{-6} \mathrm{M}$ & $5 \cdot 51 \pm 0.09$ \\
Ouabain $10^{-6} \mathrm{M}$ & $4.93 \pm 0.43$ \\
& $\mathrm{n}=4$ \\
\hline
\end{tabular}


taken up and the concentration ratios did not differ significantly from the blanks.

\section{Discussion}

Noradrenaline uptake was demonstrable at low external amine concentrations, was temperature sensitive, and was inhibited by increasing the external amine concentration and by desipramine, amitriptyline, and ouabain; adrenaline was taken up whereas isoprenaline was not. These are the features of the neuronal uptake process and it, therefore, appears that noradrenaline was being taken up by the sympathetic neurones of the right atrial samples. This study is the first demonstration of the neuronal uptake process in human cardiac muscle. It is likely that the techniques we have used would underestimate the velocity of the uptake process which may be more rapid in vivo (Petch, 1977).

The depressant effect of cardiac failure on the neuronal uptake process has been shown in the heart muscle of experimental animals (Fischer et al., 1965; Spann et al., 1965; Sassa, 1971); it is also suggested by the results obtained in the present study. However, all patients with cardiac failure had received treatment with digitalis glycosides whose inhibitory effect on ${ }^{3} \mathrm{H}$-noradrenaline uptake was confirmed in a separate experiment. Thus, it is possible that both the presence of cardiac failure and treatment with cardiac glycosides contributed to the depression of noradrenaline uptake observed in the samples of right atrial muscle taken from patients undergoing valve replacement and the relative importance of the two factors cannot be determined.

Regional differences in the activity of the neuronal uptake process, like the differences in catecholamine concentration, reflect the density of sympathetic innervation (Iversen, 1967). The greater uptake of ${ }^{3} \mathrm{H}$-noradrenaline by human right atrial muscle slices compared with left ventricular muscle was thus in keeping with our earlier observation of a higher noradrenaline concentration in the former (Petch and Nayler, 1979).

The clinical importance of the neuronal uptake process is that it determines the concentration of catecholamines at the cardiac adrenoceptor. Thus those factors that impair neuronal uptake such as an autonomic neuropathy, cardiac failure, and ischaemia, and the presence of digitalis glycosides or tricyclic antidepressants, will potentiate the cardiac effects of adrenaline and noradrenaline.

\section{References}

Fischer, J. E., Horst, W. D., and Kopin, I. J. (1965). Norepinephrine metabolism in hypertrophied rat heats. Nature, 207, 951-953.

Iversen, L. L. (1963). The uptake of noradrenaline by the isolated perfused rat heart. British fournal of Pharmacology and Chemotherapy, 21, 523-537.

Iversen, L. L. (1967). The Uptake and Storage of Noradrenaline in Sympathetic Nerves. Cambridge University Press, Cambridge.

Iversen, L. L. (1973). Catecholamine uptake processes. British Medical Bulletin, 29, 130-135.

Petch, M. C. (1977). Cardiac catecholamines. M.D. Thesis, University of Cambridge.

Petch, M. C., and Nayler, W. G. (1979). Concentration of catecholamines in human cardiac muscle. British Heart fournal, 41, 340-344.

Sassa, H. (1971). Mechanism of myocardial catecholamine depletion in cardiac hypertrophy and failure in rabbits. Fapanese Circulation fournal, 35, 391-403.

Spann, J. F., Jr., Chidsey, C. A., Pool, P. E., and Braunwald, E. (1965). Mechanism of norepinephrine depletion in experimental heart failure produced by aortic constriction in the guinea pig. Circulation Research, 17, 312-321.

von Euler, U. S. (1972). Synthesis, uptake and storage of catecholamines in adrenergic nerves. The effect of drugs. In Handbook of Experimental Pharmacology, XXXIII. Catecholamines, pp. 186-230, ed M. Blaschko and E. Muscholl. Springer-Verlag, Berlin.

Requests for reprints to Dr M. C. Petch, Papworth Hospital, Papworth Everard, Cambridge CB3 8RE. 